International Journal of

\title{
Business
}

Intelligence and

\section{Data Mining}

Editor-in-Chief:

Dr. M.A. Dorgham

Visit www.inderscience.com/ijbidm for more information and sample articles 


\section{Scope of the Journal}

ISSN: 1743-8187 (Print), ISSN: 1743-8195 (Online)

IJBIDM provides a forum for state-of-the-art developments and research as well as current innovative activities in business intelligence, data analysis and mining. Intelligent data analysis provides powerful and effective tools for problem solving in a variety of business modelling tasks. IJBIDM highlights intelligent techniques used for business modelling, including all areas of data visualisation, data pre-processing (fusion, editing, transformation, filtering, sampling), data engineering, data mining techniques, tools and applications, neurocomputing, evolutionary computing, fuzzy techniques, expert systems, knowledge filtering, and post-processing.

\section{Topics covered include:}

- Data extraction/reporting/cleaning/preprocessing

- OLAP, decision analysis, causal modelling

- Reasoning under uncertainty, noise in data

- Business intelligence cycle

- Model specification/selection/estimation

- Web technology, mining, agents

- Fuzzy, neural, evolutionary approaches

- Genetic algorithms, machine learning, expert/hybrid systems

- Bayesian inference, bootstrap, randomisation

\section{Not sure if this title is the one for you?}

Visit the journal homepage at www.inderscience.com/ijbidm where you can:

- View sample articles in full text HTML or PDF format

- Sign up for our free table of contents new issue alerts via e-mail or RSS

- View editorial board details

- Find out how to submit your papers

- Find out about subscription options, in print, online or as part of a journals collection

You can order online at www.inderscienceonline.com or download an order form from www.inderscience.com/subform.

This title is part of the Management and Business Collection (see www.inderscience.com/mb). For library collection subscriptions or for a free institutional online trial, please contact subs@inderscience.com. 